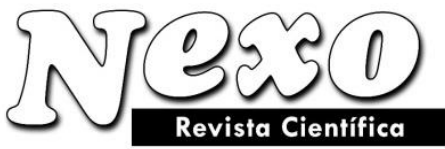

ISSN-E 1995-9516

Universidad Nacional de Ingeniería COPYRIGHT @ (UNI). TODOS LOS DERECHOS RESERVADOS

http://revistas.uni.edu.ni/index.php/Nexo

https://doi.org/10.5377/nexo.v33i02.10780

Vol. 33, No. 02, pp. 409-422/Diciembre 2020

(c) (i) $(-)$

\title{
Routing cross-docking depots, considering the time windows and pricing routes (case study: container transportation of Chabahar port)
}

\section{Enrutamiento de almacenes cruzados considerando ventanas de tiempo y precios de ruta (estudio de caso: transporte de contenedores del puerto de Chabahar)}

\author{
Farhad Bavar ${ }^{1}$, Majid Sabzehparvar, ${ }^{2, *}$, Mona Ahmadi Rad ${ }^{1}$ \\ ${ }^{1}$ Department of Industrial Engineering, North Tehran Branch, Islamic Azad University, Tehran, \\ Iran. \\ ${ }^{2}$ Department of Industrial Engineering, Karaj Branch, Islamic Azad University, Karaj, Iran. \\ *Corresponding author email: sabze@kiau.ac.ir
}

(recibido/received: 30-July-2020; aceptado/accepted: 03-November-2020)

\begin{abstract}
In this study, we develop a model for routing cross-docking centers considering time windows and pricing routs. In this model picking and delivery in several times is permitted and each knot can be serviced by more than one vehicle. Every truck can transport one or more product, in other words, we consider compatibility between product and vehicle. This model includes two goals: reducing the total cost and reducing the cost of carrying goods (freight fare). The total cost includes the cost required to traverse between the points, the cost of traversing the routes between the central cross-docking center and the first points after moving, and the cost to traverse the routes between the last points in each route and the depots that must be minimized. In general, the purpose of the model is to obtain the number of cross-docking center, the number of vehicles and the best route in the distribution network. We present a nonlinear programming model for this problem. We have solved the proposed model by GAMS. As the dimensions of the problem increase, the implementation time of the program increases progressively. So, in order to solve the model in medium and large scales, we proposed a genetic meta-heuristic algorithm. The results of examining different issues by the meta-heuristic approach show the very high efficiency of the developed algorithms in terms of the solution time and the answer of the problem.
\end{abstract}

Keywords: Cross-Docking Center, Routing, Multi-Product, Time Windows, Pricing, Supply Chain

\section{RESUMEN}

En esta investigación, se presenta un modelo para el enrutamiento entre almacenes con ventanas de tiempo y precios de ruta. En este modelo, se permite la recogida y entrega en varias ocasiones y cada nodo puede recibir servicio con más de un vehículo. Cada camión puede transportar uno o más tipos de mercancías, es decir, se considera la compatibilidad entre la mercancía y el vehículo. En este modelo, hay dos objetivos, 
que incluyen reducir el costo total y reducir el precio de envío de mercancías (flete). El costo total incluye el costo de recorrer los senderos entre los puntos, el costo de recorrer los senderos entre el almacén de la intersección central y los primeros puntos después de la salida, y el costo de recorrer los senderos entre los últimos puntos de cada sendero y los almacenes que deben minimizarse. En general, el propósito del modelo es obtener el número de almacenes, el número de vehículos y la mejor ruta en la red de distribución. Y presentamos un modelo de programación no lineal para este problema. Hemos resuelto el modelo propuesto con GAMS. A medida que aumenta el tamaño del problema, el tiempo de ejecución del programa aumenta considerablemente. Por tanto, para resolver el modelo en medianas y grandes dimensiones, presentamos el algoritmo genético metaheurístico. Los resultados de examinar varios problemas con metaheurísticas muestran la altísima eficiencia de los algoritmos propuestos en términos de tiempo de resolución de problemas.

Palabras claves: Almacén cruzado, enrutamiento, múltiples productos básicos, ventanas de tiempo, precios, cadena de suministro

\section{INTRODUCCIÓN}

Location of facilities is one of the issues has been extensively studied by researchers (Hasani Goodarzi \& Zegerderi, 2016). In the past few decades, several efforts have been devoted to develop a location model for supply networks (Li D \& Dong M 2009). Locating facilities plays an important role in the strategic planning of supply chain and has a long-term effect on its performance, because opening and closing facilities permanently and transferring to another place generates extremely high cost (Wesolosky, G.O. 1973). Therefore, decision making for locating facilities is costly and critical in terms of time, and for the reason the cost and time are the two main and effective criteria in the relevant models (Reddivari Himadeep Reddy, Sri Krishna Kumar, Kiran Jude Fernandes, ManojKumar Tiwari, 2016). When the acceptable (candidate) places of facilities already are given, it is treated as discrete locating problem, although these types of problems occur rarely in the real world (Lin et al. 2014). In the most cases, capacity of the facilities is limited because of space constraints, human force limitations and etc., although this is not the case for many problems (M.Y. Maknoon, F. Soumis, P. Baptiste, 2016). So these problems are classified into two types; problems with limited capacity and unlimited capacity (Amalia I. Nikolopoulou, Panagiotis P. Repoussis , Christos D. Tarantilis , Emmanouil E. Zachariadis).

Cross-docking center is a logistic strategy in order to reduce inventory and increase costumers' satisfaction (Buijs et al. 2014). Goods are delivered to the costumers from supplier through the crossdocking centers and items have to be gathered in the cross-docking center before sending to customer and after the weighting, packing and classifying operations are performed according to the destination, are sent out to the customers within the shortest possible time (Rodolfo Dondo Jaime Cerd'). Cross-docking center operates mostly as coordinator of inventories than play the role of storage (Peng-Yeng Yin, Ya-Lan Chuang). Goods usually are stored for less than 24 hours in the cross-docking center and it has to be discharged in the end of the day (Reddivari Himadeep Reddy, Sri Krishna Kumar, Kiran Jude Fernandes, ManojKumar Tiwari, 2016). Rohrehr has defined the cross-docking center as a method of distributing and transporting goods for the direct transport of them from the place of receipt to the post (Rohrehr, 1995). Kinnear has defined the cross-docking center as "receiving goods from a supplier or producer for different end purposes and combining these goods with the other supplier's products for the final purposes" (Kinnear, 1997). Cross-docking center has many advantages such as: reducing costs, reducing the time of provision and delivery, promoting customers servicing, reducing storage space, reducing the period of inventory circulation, reducing excess inventory keeping, integrating cargos, promoting the utilization of resources (for example, using the maximum capacity of vehicle), better adjustment between the transported goods and the rate of demand. Thus cross-docking implementation has many benefits (Hasani Goodarzi \& Zegerderi, 2016). In the supply chain management the cross-docking center is a logistic method to minimize the depot storage and coordinate the distribution operations related to the loading goods between the submission of vehicles and transporting goods. In general, five activities are performed 
in the distribution centers: reception, organization, temporary keeping, selection and transfer. Due to the lack of storage space, operations of cross-docking centers have to be exactly coordinated (Witt, 1998; Vis and Roodbergen, 2008; Miao et al., 2009; Tang and Yan, 2009).

In this study, a routing model has been developed in the multi-product state and taking into account different vehicles (ship and truck) and multi-route (multi-aspect transportation) considering the transportation pricing. Also in view of the number and type of the goods released in the port and the volume of the import goods, the cross-docking center is selected such that cover the all goods. The goods imported by ships to the cross-docking center located at Chabahar Port (Iran) are moved into the vehicles after classification. Then the shortest route for each vehicle to the cross-docking centers, are built in the provinces centers (Pre-determined locations), will be considered. After discharging goods in the depots available in the provinces centers, the items are classified and sent to the final customers. It is worth noting that some goods are transported directly to the vehicles located in cross-docking centers (different vehicles are considered, meaning that the vehicle is discharged after the end of the route and arriving to the cross-docking center and a new vehicle transport the goods for the customers). The study aims to determine the minimum total shipping costs (distribution cost, operational cost) and minimize the cost of transporting goods. Due to the limited capacity of the vehicles and fuel prices as well as the time windows of the problem, there may be transportation restrictions for the products that can affect many of the decisions related to routing. One of the most important of these decisions is the pricing the products transportation that always has many challenges and will have different consequences. In this research, a given price has been considered for transporting each unit of goods. The price depends on the route traveled by each vehicle.

The routing of this research is designed by the time windows. The problem of VRP(Vehicle routing problem) with time window (VRPTW) is the generalization of the CVRP (Capacity vehicle routing problem)problem in which the customer servicing must be delivered to each customer within a given time window. Due to providing a service within a given time window, although, the problem becomes more complicated, it will be very close to a real world applications. Given the above, the time window for routing trucks arises. Also the time windows suggested for this problem is of hard type, meaning that the vehicles have to give service within a given time window to customers. As routing vehicle is an important part of the distribution network of the cross-docking center and given the author's interest and the lack of research in this regard made researcher to study in this area. In this study the fine of keeping inventory also is considered in the model, that is: a given time widow is determined to keep goods in the depot that if it isn't discharged a fine will be considered. Another issue is pricing the transportation which is very important considering the high cost of fuel in the world and is much useful innovation that is seen in less study. At the end, the aims of this study include reducing the transportation costs, reducing the costs of keeping in the depot of distribution centers, determining the optimal routes to distribute demands and also minimizing the goods transportation pricing.

\section{THEORETICAL BASES}

Cross-docking center first was used in 1930 in the USA transportation industry and in 1950 was implemented by USA Army and in 1980 Wall-Mart, one of the largest American chain companies, has used cross-docking in the retail section, not aiming to store inventory but the depots played the coordinator of the inventory (Stalk, Evans, Shulman, 1992). Many reports presented about the successful use of the cross-docking, for example, Kodak Company (Cook, Gibson, MacCurdy, 2005), automotive industry like Toyota (Witt, 1998) and Federal Express can be mentioned. Kinnear (1997) defined the cross-docking as "receiving goods from a supplier or manufacturer for different final purposes and combining the product with the other suppliers' products for the final purposes". In this definition the focus is on the integration of products to reduce the transportation cost. Mitsubishi Heavy Industries America (MHIA) has defined cross-docking as "process of transferring goods from sending door to the receiving door without placing in storage locations", that its focus is on transferring a product from one vehicle to another. But cross-docking requires receiving, integrating and preserving goods until deliver it 
to destinations. Therefore, items have to be gathered in the cross-docking center before sending to customers. Cross-docking center shifts concentration from management of supply chain to the management of demand chain. Many organizations applied the combination of traditional warehousing and cross-docking to utilize the benefits of the both methods (Apte, Viswanathan, 2000). Also using the cross-docking center of transporting goods makes it possible to use the complete capacity of vehicle instead of using its less capacity (Agustina, CKM, Piplani, 2010).

Another distinction between the cross-docking centers appears when a customer is allocated to the dedicated items (Yan, Tang, 2009). In the pre-distribution cross-docking center, the customer is allocated before the cargo is moved from supplier that results in the faster movement of goods in the cross-docking. In the post-distribution cross-docking the allocation of goods to customers is made in the cross-docking.

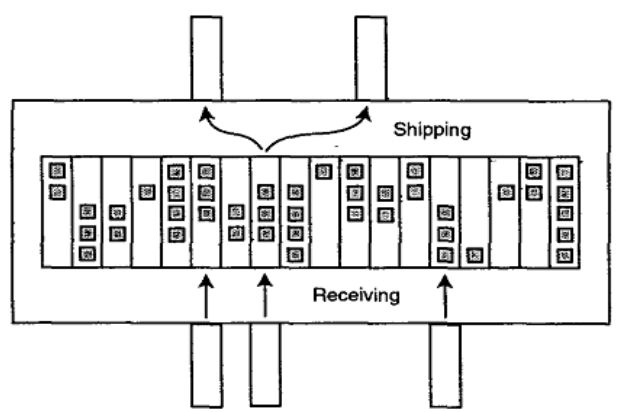

Figure 1. single-stage cross-docking center (adopted from Gue KR, Kang K, 2001)

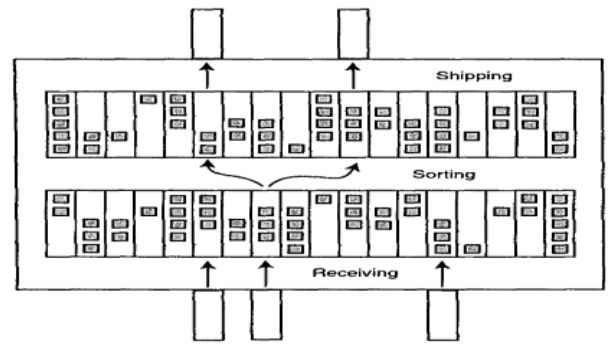

Figure 2. two-stage cross-docking (adopted from Gue KR, Kang K, 2001)

The characteristics of cross-docking center can be classifed into three types: physical, operational and related to the material flow (Von bele et al., 2012). In order to transport goods from the cross-docking center to numerous costomers we require loading from several suppliers. The both processes of picking products from suppliers by vehicles before integration in the cross-docking and sedning it to customers by vehicle are the problem called vehicle routing.

The first research conducted in the vehicle routing area for cross-docking was performed by Le et al. (2016) to obtain the schedule for optimal routing of vehicles and has considered the simultaneous model of scheduling and routing the cross-docking and as the problem is NP-HARD, they have developed an algorithm based on the forbidden search to solve the problem. Wen et al (2009) presented the well-known article of routing cross-dcoking (VRPCD) by different vehicles and taking into account that goods can't be stored in the cross-docking. They proposed the forbiden search algorithm to solve the model. Hasani Goodarzi \& Tavakoli Moghadam (2012) developed the model of vehicle routing and considering the time windows, multi-products state and picking and delivering in several times. The problem of vehicle routing with Multi-Depot VRP (MDVRP) is a special type of VRP problem in which instead of one depot several depots are used. In this problem the location of each depot and its capacity has been determined previously. Each depot has a number of homogeneous vehicles with equal capacity that have been considered for transportation of product from depot to customers, that the number and capacity of vehicles have been already determined. The whole products of a factory are stored in the depots to distribute 
between customers. Coordinates of each customer's location and the amount of his/her demand of a product has been determined previously. Each customer receives his/her demand only from one vehicle. The problem of vehicle routing by time windows (VRPTW) is a generalization of CVRP problem in which providing service to each customer must be taken place in a certain time window. Although, providing service in a particular time window has many complications, if the constraint of the route length and the cost of time window are added, the problem is approached to a real world application. Among the given VRPTW instances can refer to dividing cash into bank branches, collecting garbage and industrial waste, dividing fuel into distribution stations and servicing schools, etc. Routing is about finding an ideal route that ensures the aims if the model and follow the customer while planning for vehicles determines the time to provide service to each customer. Providing service to each customer is started within its appropriate time window, and the machine in the location of each customer has to be stopped by the size of the servicing time Si (Toth and Wigo, 2002).

Literature on the area of the pricing issue focuses mainly on the linear demands with a percentage of error, given the convincing and influential analyzes. In the past, study has been made on any part of the aforementioned areas and some opportunities have been provided to the other researchers for future research. The importance of pricing financial assets has resulted in the appearance of various theories and models during the recent half a century. The models of Marquoitz (1952), Sharp, (1963), Linter (1965), Mousine (1966), Ross (1976) and Shoulz (1973) are among the most important models. There an extensive literature on the controlling inventory, pricing and management of income. For example, Zipkin (1999) and Porteus (1990) in their books have studied the techniques of management of inventory, while Taloorai and Erzin (2004) in their book have provided a good review of literature on the pricing and management.

\section{PROBLEM DEFINITION}

In this study, a routing model has been developed in the multi-product state and taking into account different vehicles (ship and truck) and multi-route (multi-aspect transportation) considering the transportation pricing. Also in view of the number and type of the goods released in the port and the volume of the import goods, the multi modal transportation is selected such that cover the all goods. The goods imported by ships to the cross-docking center located at Chabahar Port (Iran) are moved into the vehicles after classification. Then the shortest route for each vehicle to the cross-docking centers, are built in the provinces centers, will be considered. After discharging goods in the depots available in the provinces centers, the items are classified and sent to the final customers. It is worth noting that some goods are transported directly to the vehicles located in cross-docking centers (different vehicles are considered, meaning that the vehicle is discharged after the end of the route and arriving to the crossdocking center and a new vehicle transport the goods for the customers).

\section{Assumptions}

The most important assumptions considered in this study are:

For each depot a minimum and maximum capacity has been considered.

The capacity of the central depot is limited.

If a new depot is built, it has to provide service customers by its minimum capacity.

The location of the depots is fixed and definite.

Picking and delivery is several cargos are allowed. That is, a customer is ready to receive an order in several times.

The work time of each vehicle is limited.

The number of vehicles is limited.

Capacity of vehicles is limited.

Vehicles have the ability to carry one or more special goods.

The time of keeping goods in the depots is limited.

Vehicles of the fleet are assumed heterogeneous. And capacity of each vehicle is different.

The route of each vehicle begins from a depot but the final depot can different from the initial one. 


\section{Notations}

Several sings and parameters have been used in the mathematical method that each is defined as following:

\section{Sets and indices}

$i, j$ : the index related to the points of discharging cargo $(i, j=1,2, \ldots, N)(i=0$ shows the depot location in the cross-docking center in the port)

$v$ : Index related to vehicles $(\mathrm{v}=1.2, \ldots, \mathrm{V})$

$s$ : Index related to depots $(\mathrm{s}=1,2, \ldots, \mathrm{S})$

$N$ : the number of points

$K$ : Index related to goods

$W$ : a sub-set of points

$V$ : a set of available vehicles

$S$ : the number of depots

$A$ : a set of all points and depots

$M$ : a very big positive number

\section{Parameters}

$\operatorname{COT}_{i j}$ : The cost of traveling the edge $(\mathrm{i}, \mathrm{j})$ between two nodes

$\operatorname{COT}_{s i}$ : The cost of traveling the edge (i,s) or the edge (s,i) between the cross-docking depot and the customer warehouse in the point

$d_{i}$ : the amount of demand

$R_{v}$ : the capacity of vehicle $\mathrm{M}$

$\alpha_{i}$ : the amount of rush time of starting service for node $\mathrm{i}$

$\beta_{i}$ : the amount of delay time of starting service for node $\mathrm{i}$

$E t_{i}$ : the earliest time each service can starts

$Q t_{i}$ : length of the time window to deliver goods in the point of discharging cargo i

$t_{v}$ : the time of discharging cargo from vehicle $\mathrm{v}$

$t_{i, j}$ : interval between the point of discharging cargo of the node $\mathrm{i}$ and node $\mathrm{j}$

$x i s_{i, j}$ : distance of the route between the point of discharging cargo of node $\mathrm{i}$ and node $\mathrm{j}$

$\psi_{i}$ : fine for violating the time unit for each node

\section{Decision making variables}

$V P_{i j v}$ : if a vehicle passes from edge $(\mathrm{i}, \mathrm{j})$ is equal to 1 otherwise 0

$V P_{s i v}$ : If a vehicle assumes delivery of product $\mathrm{K}$ to some points is equal to 1 otherwise 0

$V P_{i s v}$ : if a vehicle passes from edge (i,s) is equal to 1 otherwise 0

$U_{i, j}$ : if no vehicle can't reach to the discharge point before the end of time window is equal to 1 otherwise 0

$\mathrm{t}_{0}$ : the time of arriving to node $\mathrm{i}$ (time of start of service for node $\mathrm{i}$ )

$w_{i}$ : the additional time spent in node $\mathrm{i}$

$\delta_{i}$ : the time of service in node $\mathrm{i}$

$Y_{t}$ : Maximum travel time for vehicles

$\lambda$ : The cost of vehicles travels for each unit of route

$\varphi$ : The level of service related to time spent by vehicles 


\section{MATHEMATICAL MODEL}

$$
\begin{aligned}
& Z_{1}=\operatorname{Min} \sum_{i=1}^{N}\left[\sum_{\substack{j=1 \\
j \neq i}}^{N} \sum_{v=1}^{V} V P_{i j v} C O T_{i j}+\sum_{s=1}^{S} \sum_{v=1}^{V} V P_{s i v} C O T_{s i}+\sum_{s=1}^{S} \sum_{v=1}^{V} V P_{i s v} C O T_{s i}\right] \\
& +\sum_{i=1}^{N} \psi_{i}\left(\alpha_{i}+\beta_{i}\right) \\
& Z_{2}=\operatorname{Min} \sum_{i=1}^{N} \sum_{\substack{j=1 \\
j \neq i}}^{N} \sum_{v=1}^{V} x i s_{i j} \cdot V P_{i j v} \cdot \lambda \\
& \sum_{i=1}^{N} V P_{i 0 v}=1 \\
& \sum_{k=1}^{N} \sum_{j=1}^{N} V P_{0 j v}=1 \\
& \sum_{v=1}^{N} \sum_{i=0}^{N} V P_{i j v}=1 \\
& \sum_{v=1}^{N} \sum_{j=0}^{N} V P_{i j v}=1 \\
& \sum_{\substack{j=1 \\
j \neq i}}^{N} \sum_{v=1}^{V} V P_{i j v}+\sum_{s=1}^{S} \sum_{v=1}^{V} V P_{i s v}=1 \\
& \sum_{s=1}^{S} \sum_{v=1}^{V} V P_{s i v}+\sum_{\substack{j=1 \\
j \neq i}}^{N} \sum_{v=1}^{V} V P_{j i v}=1 \\
& \sum_{s=1}^{V} \sum_{i=1}^{N} V P_{s i v}-\sum_{j=1}^{N} \sum_{s=1}^{S} V P_{i s v}=0 \\
& \sum_{s=1}^{S} \sum_{i=1}^{N} V P_{s i v} d_{i}+\sum_{i=1}^{N} \sum_{\substack{j=1 \\
j \neq i}}^{N} V P_{i j v} d_{j} \leq R_{v} \\
& \sum_{s=1}^{S} V P_{s i v}+\sum_{\substack{j=1 \\
j \neq i}}^{N} V P_{j i v}-\sum_{\substack{j=1 \\
j \neq i}}^{N} V P_{i j v}-\sum_{s=1}^{S} V P_{i s v}=0 \\
& \sum_{i=1}^{N} \sum_{\substack{j=1 \\
j \neq i}}^{N} V P_{i j v} \leq\left(\sum_{s=1}^{S} \sum_{i=1}^{N} V P_{s i v}\right) * M \\
& P\left\{\sum_{i=1}^{N} \sum_{j=1}^{N} t_{i j} V P_{i j v}+\sum_{i=0}^{N}\left(\delta_{i}+w_{i}+s_{v}\right) \sum_{j=1}^{N} V P_{i j v} \leq Y_{t}\right\} \geq \varphi
\end{aligned}
$$




$$
\begin{array}{cc}
\sum_{\substack{i \in W \\
\text { j } \\
j \neq i}}^{N} V P_{i j v} \leq|W|-1 & \forall v \quad \forall W \subseteq A \backslash\{Z\},|W| \geq 2 \\
t_{0}-Q t_{i} \leq \mathrm{M} . \mathrm{U}_{i j} & \forall i, j \\
\alpha_{i} \geq E t_{i}-t_{0} & \forall i \\
\beta_{i} \geq t_{0}-Q t_{i} & \forall i \\
V P_{i j v} \in\{0,1\} & i \neq j \\
V P_{s i v} \in\{0,1\} & \forall i, s, v \\
V P_{i s v} \in\{0,1\} & \forall i, s, v \\
U_{i j} \in\{0,1\} & \forall i, j \\
t_{0}, \mathrm{w}_{i}, \delta_{i}, F, \lambda, \varphi \geq 0 & \forall i
\end{array}
$$

The constraint (1) is related to the first target function. The target function has been constituted of four parts; including the cost needed to travel the routes between the points, the cost needed to travel the routes between the central cross-docking depot and the first points after moving and the cost needed to travel the routes between the last points in every route and depots and, finally, the cost of lack of timely service to the points that have to be minimized.

The constraint (2) is related to the second target function. This target function is the cost of transporting goods in the routes that has to be minimized.

The constraint (3) to (6) indicate the conditions of allocating vehicle to the points of discharging cargo and the type of goods. The constraints (7) and (8) guarantees that each node in every period is met once. The constraint (7) guarantees that an edge is traveled by a vehicle if the vehicle has started its route from the cross-docking center and it makes that a node either is located at the beginning of the route after the crossdocking or after other node, and in the constraint (8) this route include the route of a node to another node and the route of a node to warehouse and it shows that output of each node can end to one warehouse or only to another node. Also these two constraints cause that the all points are provided with service. The constraint (9) is related to the beginning and end of each route that guarantees that each route starts from the central cross-docking depot and ends to a warehouse. The constraint (10) is related to the capacity of each vehicle that the total demand of points in one route by each vehicle wouldn't be exceeded from the capacity of vehicle. The constraint of (11) causes that the input and output to each node by every vehicle is equal. And each node receives service only and only by one route. The constraint (12) guarantees that one edge can be traveled by a vehicle if it starts its route from one warehouse. The constraint (13) guarantees that the level of vehicles service wouldn't exceed from a given level. The constraint (14) prevents from developing sub-tours (travel between warehouses). The constraint (15) guarantees that if any vehicle can't reach to destination before the time window. The constraint (16) and (17) is related to the time window). The constraint (18) to (21) is related to the allowed values for design making variables of the model that all are of zero and one type. The constraint (22) also is related to the non-negative variables. 


\section{Solving the proposed mathematical model}

Given that the mathematical model proposed in the previous sections has large number of zero and one variable, solving the problem in the large dimensions has problems that genetics algorithm can be an appropriate method to solve such problems. Therefore, in this study, the genetics algorithm GA has been used to solve the model. Whilst, to solve the problem more accurately in the small dimensions the GAMS program has been used.

Taguchi stated that factors are divided into two classes: controllable factors and disturbance factors. Using this method, the disturbance factors are outside the orthogonal array and the controllable factors are within the inner array. The objective of the method is to find optimal levels of controllable factors and minimize the effect of disturbance factors. In this method, the qualitative characteristics of the measured values of the experiments are converted into signal-to-noise ratio $(\mathrm{S} / \mathrm{N})$. This rate shows the level of deviations displayed in the response variable. In this study, the $\mathrm{S} / \mathrm{N}$ ratio has a "the bigger the better" feature; because the value of the target function of this problem (total cost) is "the less the better." In Tagochi's method this index is defined as following:

$$
\mathrm{S} / \mathrm{N} \text { ratio }=-10 \log _{10}(\text { objectivefunction })^{2}
$$

If the sub-menu of the experiments design of MINITAB.14 program is used to which we enter the values obtained from different experiments, the program, after performing statistical analyzes presents the 2 diagrams of the effects of the average data on the $\mathrm{S} / \mathrm{N}$ indices and the diagram of the effects of the data average on the averages as output.

In the figure (1) the values of $\mathrm{S} / \mathrm{N}$ rate have been displayed for different levels. As it is evident in the figure, the deviations of the algorithm are reduced when the parameters of the problem are set to these values: cross rate, level 1; mutation rate, level and combination of the primary population and generation on the level.The diagram of the effects of the data average on the averages, in figure 1, also conform the results obtained from $\mathrm{S} / \mathrm{N}$ diagram.

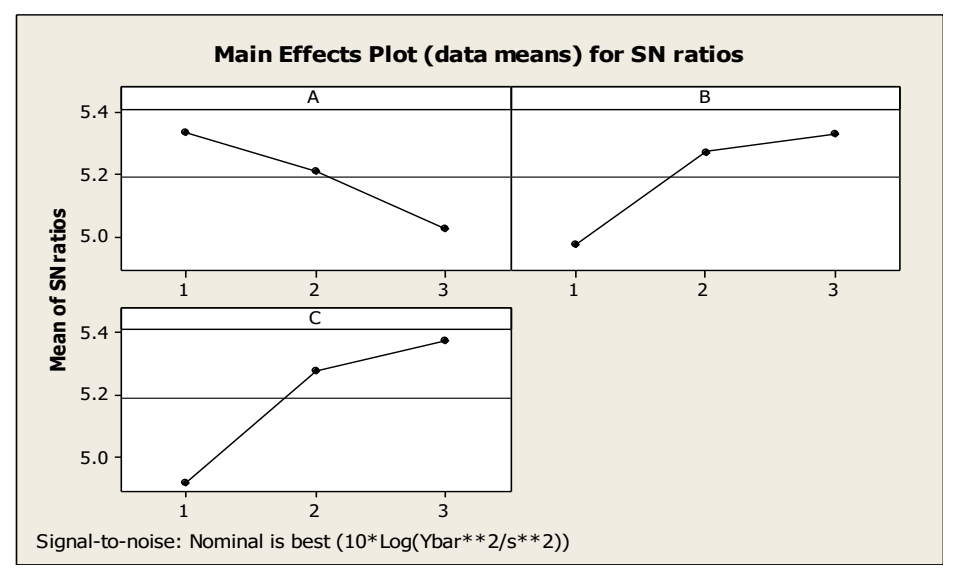

Figure 3. diagram of $\mathrm{S} / \mathrm{N}$ rate of the target functions in the different levels of factos 


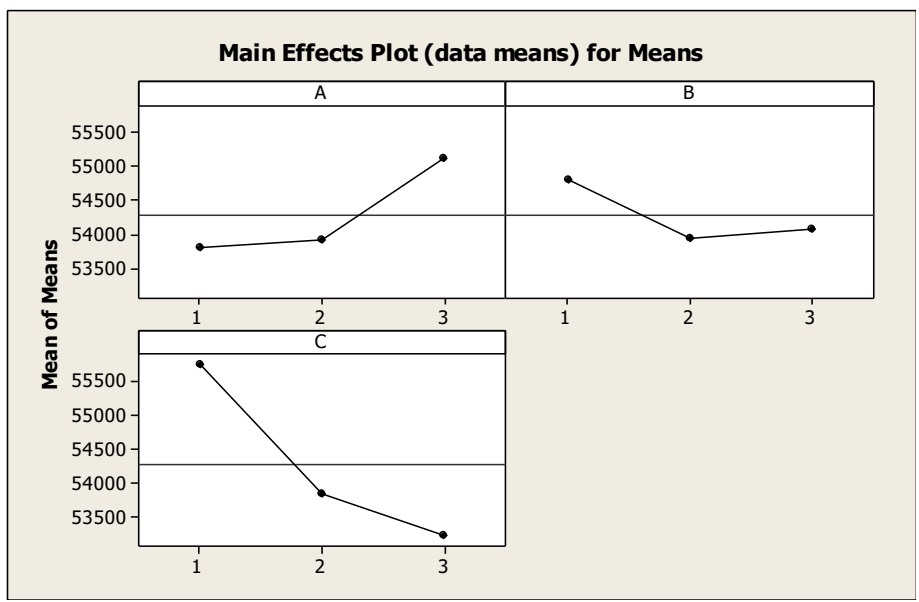

Figure 4. diagram of the effects of the data average on the averages, in different levels of factors

Also in order to take into account the behavior of the genetic algorithm according to the determined indices, the diagram of the motion of this algorithm toward an optimal solution for a problem with 6 depots, 3 depot locations and 4 types of goods was dpicted. This diagram is shown in Fig. 5.

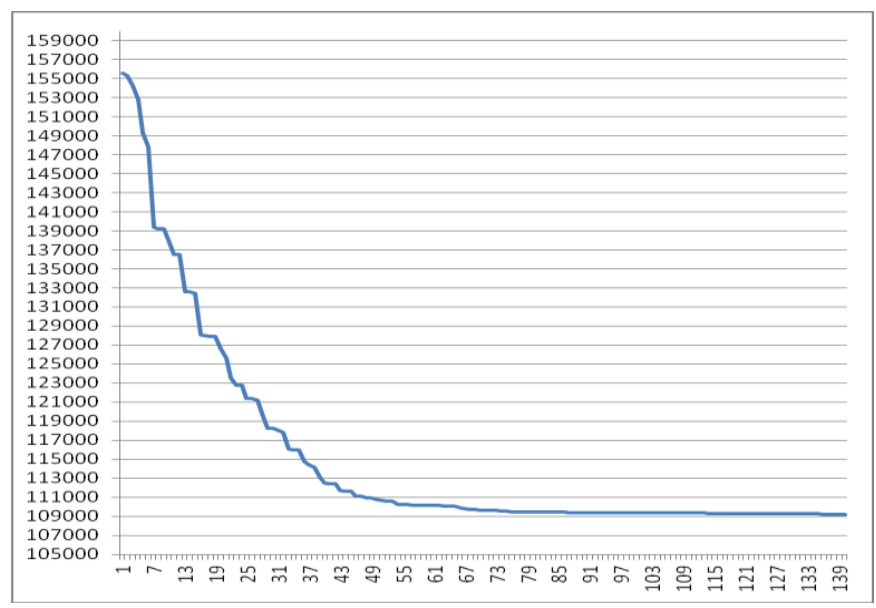

Figure 5. Diagram of the motion of the proposed genetic algorithm

\section{COMPUTATIONAL RESULTS}

Now that the optimal levels of the parameters of the proposed algorithm for our concerned problem model has been obtained using Tagochi's method, we can compare the results obtained from the implementation of the proposed algorithm with the exact solutions (if any) of the GAMS program in terms of the value of the target function and the time of resolution. The problems have been generated in two small and large groups and totally the results of the calculations for the 24 problems have been presented in table (1) and (2). In the presented tables, $\mathrm{t}(\mathrm{s})$ is the computational time in second; (opt) and (local) show the values of the final and local optimal target function of the GAMS program, respectively. Also, the average values and the best answer resulting from 5 times of running the genetic algorithm are shown in the mean and best columns, respectively. In the column t.av(s), the average GA time in 5 runs in second and in the GAP column the difference between the values of GA.mean and GAMS is shown in the sub-column A and the difference between the values and GA.best and GA.mean in the sub-column B. 
Table 1. Computational results for small problems

\begin{tabular}{|c|c|c|c|c|c|c|c|c|c|c|c|c|}
\hline \multirow[t]{2}{*}{ No. } & \multirow[t]{2}{*}{$\mathbf{S}$} & & \multirow[t]{2}{*}{$\mathbf{N}$} & \multirow[t]{2}{*}{$\mathbf{K}$} & \multirow[t]{2}{*}{$\mathbf{V}$} & \multicolumn{2}{|c|}{ GAMS } & \multicolumn{3}{|c|}{ GA } & \multicolumn{2}{|c|}{ GAP } \\
\hline & & & & & & $\mathrm{t}(\mathrm{s})$ & optimal & $\mathrm{t} \cdot \mathrm{av}(\mathrm{s})$ & mean & best & $\mathbf{A}$ & B \\
\hline 1 & 2 & & 10 & 20 & 2 & 1 & 9595 & 20 & 9595 & 9595 & 0 & 0 \\
\hline 2 & 2 & & 10 & 20 & 2 & 6 & 12854 & 25 & 12875 & 12855 & 21 & 20 \\
\hline 3 & 2 & & 11 & 20 & 3 & 31 & 16134 & 29 & 16557 & 16513 & 423 & 44 \\
\hline 4 & 2 & & 12 & 23 & 3 & 18 & 18620 & 31 & 18620 & 18620 & 0 & 0 \\
\hline 5 & 3 & & 12 & 23 & 3 & 74 & 17772 & 39 & 17780 & 17747 & 8 & 33 \\
\hline 6 & 3 & & 15 & 25 & 4 & 164 & 21947 & 29 & 22185 & 22185 & 238 & 0 \\
\hline 7 & 3 & & 15 & 25 & 4 & 132 & 19983 & 38 & 20085 & 20047 & 102 & 38 \\
\hline 8 & 3 & & 20 & 27 & 4 & 178 & 25726 & 33 & 25761 & 25727 & 35 & 34 \\
\hline 9 & 3 & & 20 & 27 & 5 & 901 & 22851 & 38 & 23046 & 22972 & 195 & 74 \\
\hline 10 & 3 & & 25 & 27 & 5 & 1809 & 28206 & 21 & 28512 & 28424 & 306 & 88 \\
\hline 11 & 3 & & 25 & 35 & 6 & 429 & 23999 & 48 & 24304 & 24275 & 305 & 29 \\
\hline 12 & & 4 & 30 & 45 & 6 & 1047 & 27208 & 60 & 27435 & 27404 & 227 & 31 \\
\hline
\end{tabular}

Table 2. Computational results for large problems

\begin{tabular}{|c|c|c|c|c|c|c|c|c|c|c|c|c|}
\hline \multirow[t]{2}{*}{ No. } & & & & & & \multicolumn{2}{|c|}{ GAMS } & \multicolumn{3}{|c|}{ GA } & \multicolumn{2}{|c|}{ GAP } \\
\hline & & & & & & $\mathrm{t}(\mathrm{s})$ & local & $\mathrm{t} . \mathrm{av}(\mathrm{s})$ & mean & best & A & B \\
\hline 13 & & 4 & 35 & 65 & 6 & 7200 & 34438 & 113 & 34920 & 34758 & -482 & 162 \\
\hline 14 & & 4 & 35 & 80 & 6 & 7200 & 34308 & 118 & 34704 & 34482 & -396 & 222 \\
\hline 15 & 5 & & 40 & 95 & 7 & 7200 & 35871 & 102 & 35266 & 35031 & 605 & 235 \\
\hline 16 & 5 & & 40 & 110 & 7 & 7200 & 42243 & 82 & 40118 & 39962 & 2125 & 156 \\
\hline 17 & 5 & & 45 & 120 & 7 & 7200 & 40829 & 78 & 40119 & 40004 & 710 & 115 \\
\hline 18 & 4 & & 45 & 135 & 8 & 7200 & 56818 & 86 & 45055 & 44683 & 11763 & 372 \\
\hline 19 & 4 & & 45 & 145 & 8 & 7200 & 60931 & 144 & 45153 & 45000 & 15778 & 153 \\
\hline 20 & 4 & & 55 & 160 & 8 & 7200 & $*$ & 107 & 68670 & 67887 & $*$ & 783 \\
\hline 21 & 4 & & 55 & 175 & 9 & 7200 & $*$ & 127 & 65166 & 64915 & $*$ & 251 \\
\hline 22 & 4 & & 65 & 180 & 9 & 7200 & $*$ & 345 & 64980 & 64582 & $*$ & 398 \\
\hline 23 & 4 & & 65 & 180 & 9 & 7200 & $*$ & 395 & 75461 & 75391 & $*$ & 70 \\
\hline 24 & 4 & & 65 & 180 & 9 & 7200 & $*$ & 886 & 107773 & 107010 & $*$ & 763 \\
\hline
\end{tabular}

The problems that the GAMS programs wasn't able to solve them within 2 hours to provide the final optimal answer for them were classified as large problems and the best answer obtained during this time was considered as final answer. For the problems no. 19 afterward, the GAMS program wasn't able to provide any answer during the determined time and this issue has been displayed by (*). The crossheuristic genetic algorithm developed for the problems to no. 12 within a short time achieve to answers with the mean deviation $.74 \%$. Likewise, for the problems no. 15 afterward, the proposed genetic algorithm achieves better answers at a much shorter time than the responses of GAMS program. Also, the difference between the optimal values and the mean genetic algorithm is on average 0.34. Figure (4) graphically shows the values of the target function obtained through the GAMS program, as well as the mean values and the best results obtained from the genetic algorithm. Similarly, Figure (5) shows the difference between the computation time of the genetic algorithm and the GAMS method. 


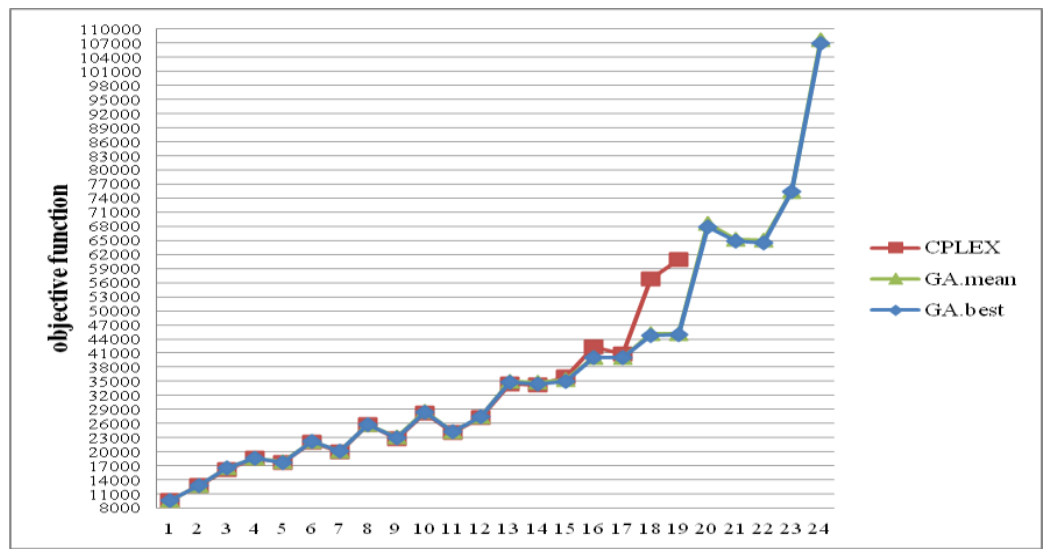

Figure 6. Display of the values of the target function in the both methods

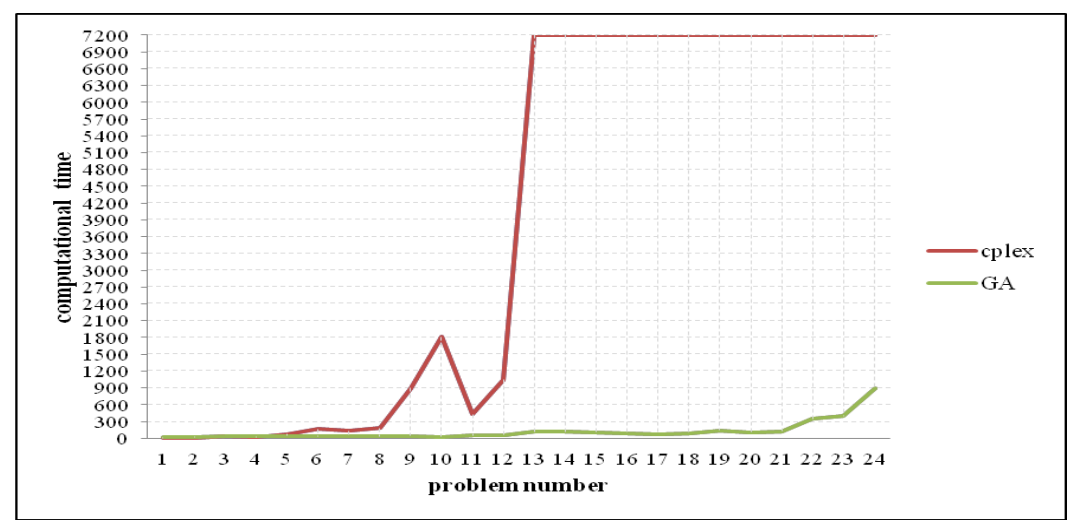

Figure 7. display of computational time obtained from the both methods

\section{CONCLUSION}

In the present study, a mathematical model for routing the cross-docking depots taking into account the time windows and the pricing of routes was investigated. The goals of this problem are to reduce the total cost and the cost of transporting goods (freight fare). The total cost includes the cost needed to travel the routes between points, the cost of traveling the routes between the central cross-docking and the first points after movement, and the cost required to travel the routes between the last points in each route and the warehouses and, finally, the cost of lack of timely service to the points that have to be minimized. The proposed problem was solved by GAMS software. As to solve problems of great size by this software is time-consuming, we developed the genetic algorithm. In order to evaluate the proposed in small-scale algorithm, we compare its answers to answers of solving by GAMS and for the large dimensions, we obtain the mean of the target function obtained in 10 repetitions for the algorithms and compared them. The efficiency of the proposed model and the applicability of algorithms for different issues were tested. The computational results showed that, although both methods are both appropriate in terms of time and in terms of the values of the target function, the genetic algorithm is more efficient than the GAMS method. As discussed earlier, the issue of routing vehicles is one of the most important and practical issues in the real world, especially in reducing costs and increasing the importance of distribution systems-providing companies and organizations that has been the focus of attention for researchers due to its wide range of 
applications. Due to the high cost of carrying goods in ports, the results of the research showed that this model can reduce the total cost of cargo transportation and clearance at Chabahar port by minimizing freight fares. In this section, suggestions are given in the development of chain structure, development of parameters, development of evaluation criteria for enthusiasts in this field. In the proposed model, the depot centers as well as warehouses are jointly considered. Each of these points can also be considered in isolation and with different characteristics in the chain. In the proposed model, focusing on freight transport can be considered in future research of other levels of supply chain. The proposed model has two objective functions, the former seeking to reduce costs and the other to reduce the price of the goods. At the same time, it is possible to consider other criteria of assessment such as chain reliability, delay in satisfaction of demand, etc. The presented model is a periodic. The researcher can extend the model to several rounds as well. fixed costs and personnel costs are assumed. The number of these parameters is assumed to be unspecified for the development of the model. Considering the community in logistics optimization models is also an interesting topic for researchers. It is also possible to identify all the factors affecting each other, and with the analysis of systems and software approach, a model with a much higher degree than the current model is presented. In future investigations, uncertainty in demand and cost can also be taken into account on the quality and quantity of goods carried.

\section{REFERENCES}

Agustina, D. Lee, CKM. Piplani, R. (2010). A review: mathematical models for crossdock planning. International Journal of Engineering Business Management, 2(2):47-54.

Apte, U.M, Viswanathan, S. (2000). Effective cross docking for improving distribution efficiencies. International Journal of Logistics: Research and Applications, 3(3):291-302.

Cook, R.L, Gibson, B, MacCurdy, D., (2005). A lean approach to cross docking. Supply Chain Management Review, 9(2):54-9.

Dondo, R. Cerdá, J. (2014). A monolithic approach to vehicle routing and operations scheduling of a cross-dock system with multiple dock doors, Computers \& Chemical Engineering, Volume 617 April 2014, Pages 184-205.

Dondo, R. Cerdá, J. (2015). The heterogeneous vehicle routing and truck scheduling problem in a multi-door crossdock system, Computers \& Chemical Engineering, Volume 76, 8 May 2015, Pages 42-62.

Glossary of the Material Handling Industry of America (MHIA). 2011.

Gue, K,R, Kang, K. (2001). Staging queues in material handling and transportation systems. In: Proceedings of the 33rd conference on winter simulation, p. 1104-8.

Hasani Goodarzi, A. Zegordi, S.H. (2016). A location-routing problem for cross-docking networks: A biogeographybased optimization algorithm, Computers \& Industrial Engineering, Volume 102, December 2016, Pages 132-146.

Kinnear, E. (1997). Is there any magic in cross-docking? Supply Chain Management: An International Journal, 2(2):49-52.

Lee, Y.H. Jung, W.J. Lee, K.M. (2006). Vehicle routing scheduling for cross docking in the supply chain, Computer and Industrial Engineering, 51:247-56.

Lin, C., Choy, K.L., Ho, G.T.S., Chung, S.H. and Lam, H. Y. (2014). "Survey of Green Vehicle Routing Problem: Past and future trends", Expert System with Application, Vol. 41, No. 4, PP. 1118-1138. 
M.Y. Maknoon, F. Soumis, P. Baptiste. (2016). Optimizing transshipment workloads in less-than-truckload crossdocks, International Journal of Production Economics, Volume 179, September 2016, Pages 90-100.

Miao Z, Fu K, Fei Q, Wang F.. (2008). Meta-heuristic algorithm for the transshipment problem with fixed transportation schedules. In: New frontiers in applied artificial intelligence, Lecture Notes in Artificial Intelligence, 5027:601-10.

Nikolopoulou, A. I. Repoussis, P. P. Tarantilis, C. D. Zachariadis, E.E. (2017), Moving products between location pairs: Cross-docking versus direct-shipping, European Journal of Operational Research, Volume 256, Issue 1 February 2017, Pages 803-819

Paul Buijs, Iris F.A. Vis, Héctor J. Carlo. (2014). Synchronization in cross-docking networks: A research classification and framework, European Journal of Operational Research, Volume 239, Issue 16 December 2014 , Pages 593-608.

Peng-Yeng Yin, Ya-Lan Chuang. (2016), Adaptive memory artificial bee colony algorithm for green vehicle routing with cross-docking, Applied Mathematical Modelling, Volume 40, Issues 21-22, November 2016, Pages 9302-9315.

Reddivari Himadeep Reddy, Sri Krishna Kumar, Kiran Jude Fernandes, Manoj Kumar Tiwari. (2016). A MultiAgent System based simulation approach for planning procurement operations and scheduling with multiple crossdocks, Computers \& Industrial Engineering, Volume 107, May 2017, Pages 289-300.

Stalk, G. Evans, P. Shulman, L.E. (1992). Competing on capabilities: the new rules of corporate strategy. Harvard Business Review, 70(2):57-69.

Vis, I.F.A. Roodbergen, K.J. (2008). Positioning of goods in a cross-docking environment. Computers \& Industrial Engineering. Vol. 54, pp. 677-689.

Wen, M. Larsen, J. Clausen, J. Cordeau, J.F. Laporte, G. (2009). Vehicle routing with cross-docking. Journal of the Operational Research Society, 60(12):1708-18.

Witt, C.E. (1998). Crossdocking: concepts demand choice. Material Handling Engineering, 53(7): 44-9.

Yan, H. Tang, S.1. (2009). Pre-distribution and post-distribution cross-docking operations. Transportation Research Part E: Logistics and Transportation Review, 45(6):843-59. 